\title{
SOBRE POSITIVISMO E EDUCAÇÃO
}

\author{
Jamil Ibrahim Iskandar* \\ Maria Rute Leal**
}

\section{Resumo}

Este trabalho apresenta uma reflexão sobre a educação segundo a filosofia positivista e, particularmente, baseado no pensamento de Comte. Faz-se uma abordagem inicial como ambiência a respeito do surgimento da filosofia positivista. Em seguida são apresentados, os itens "positivismo e educação", "o positivismo e a escola", "positivismo na educação brasileira" e, para finalizar, há uma tomada de posição quanto à educação segundo os critérios positivistas.

Palavras-chave: Educação, Positivismo, Escola Tecnicista, Educação Brasileira.

\section{Abstract}

This paper presents a reflection upon education according to the positivist philosophy particularly based on Comet's ideas. It starts out with an introduction about the emergence of the positivist philosophy and follows on with the topics "positivism and educations", "positivism and the school", "positivism in the Brazilian Education". To conclude, a position is taken regarding education according to the positivist criteria.

Keywords: Education, Positivism, Technicist pedagogy, Brazilian Education.

\section{Introdução}

O pensamento do século XIX não foi apenas influenciado por mudanças econômicas e sociais, também deve ser compreendido de acordo com o momento em que se encontravam a filosofia e a ciência. No século XVIII, Kant havia desenvolvido importantes reflexões sobre as possibilidades e limites da razão. Neste mesmo século, diferentes linhas filosóficas interpretaram 0 pensamento kantiano; entre elas encontra-se o Positivismo.

Geralmente, o francês Augusto Comte (1798-1895) é o mais conhecido como o iniciador da corrente positivista. Todavia, do ponto de vista histórico, vê-se que as idéias positivistas já se encontravam difundidas na socieda-

* Professor no Programa de Pós-Graduação, Mestrado em Educação, na Pontifícia Universidade Católica do Paraná.

Email: skandjal@rla01.pucpr.br

** Mestranda em Educação da Pontifícia Universidade Católica do Paraná.

Email: rute_leal@hotmail.com 
de antes mesmo do período de atividade de Comte. É importante ressaltar que Comte recebeu influência de Turgot, Condercet e Saint-Simon. Antoine Nicolas de Condercet (1666-1790) defendia a idéia de que toda e qualquer ciência da sociedade precisa se identificar com o que ele chamava de matemática social, isto é, precisa realizar um estudo preciso, rigoroso, numérico dos fenômenos sociais. Segundo Condorcet, a ciência estava sendo controlada e submetida aos interesses de senhores feudais, à aristocracia e ao clero e carecia de objetividade. Portanto, de acordo com Condorcet, era necessário tirar o controle das ciências destas classes para que uma ciência natural pudesse se impor (MESQUIDA, 2001).

Foi Claude Henri de Saint-Simon (1760-1852) o primeiro a utilizar o termo positivo na ciência. Para ele, o raciocínio deveria se basear nos fatos observados e discutidos. Nesse sentido, percebe-se a tendência de negação da metafísica. "Uma vez que nosso conhecimento está uniformemente fundado em observações, a direção de nossos interesses espirituais deve ser entregue ao poder da ciência positiva" . (COMTE In: MESQUIDA, 20001, p.27) SaintSimon também defendeu a sociedade industrial, dizendo que o que é favorável à indústria também o será para o homem.

No século XIX Comte formaliza as idéias positivistas. Quando Comte falou da importância do conhecimento científico, não estava apenas defendendo uma orientação epistemológica, estava apresentando uma maneira de pensar e de realizar as transformações sociais. "O pensamento positivista poderia garantir a organização racional da sociedade", dizia ele.

O pensamento de Comte apresenta as seguintes preocupações fundamentais: uma filosofia da história na qual encontram-se as bases de sua filosofia positivista e as três fases da evolução do pensamento humano: 0 teológico, 0 metafísico e o positivo. Após passar pelos três estágios históricos, no estágio científico abandona-se a referência às causas últimas, ou seja, às não observáveis.

A organização científica da sociedade irá atender à necessidade de estabilidade. "O conhecimento das leis da sociedade permitirá aos cidadão verem os limites das reformas possíveis, ao passo que os governos serão capazes de usar o conhecimento social científico como base para reformas paulatinas e efetivas que aumentarão mais ainda o consenso" (BOTTOMORE, 1988, p. 291).

A fim de libertar a teoria social da teologia e da metafísica, Comte apóia-se no que ele chama de "espírito autêntico" do positivismo, ou seja, a invariabilidade das leis físicas pois,

A filosofia teológica e a filosofia metafísica nada mais dominam hoje em dia senão o sistema do estudo social. Elas devem ser expulsas deste último refúgio. Isto será feito principalmente pela interpretação básica do movimento social como necessariamente sujeito a leis físicas invariáveis, em lugar de ser governado por qualquer espécie de vontade (COMTE, 1978, p.16). 


\section{Positivismo e educação}

O Positivismo influenciou de maneira considerável a sociedade nos séculos XIX e XX. Tendo em vista que a Educação é uma atividade social, também foi marcada por esta influência. Nas escolas, a influencia do positivismo se fez sentir com força devido à influência da Psicologia e da Sociologia, ciências auxiliares da Educação.

O positivismo esteve presente de forma marcante no ideário das escolas e na luta a favor do ensino leigo das ciências e contra a escola tradicional humanista religiosa. O currículo multidisciplinar - fragmentado - é fruto da influência positivista.

No Brasil esta influência aparece no início da República e na década de 70, com a escola tecnicista. Foi muito divulgado por intermédio do Apostolado Positivista que se incorporou ao movimento pela proclamação da república e da elaboração da constituição de 1891. O movimento republicano apoiou-se em idéias positivistas para formular sua ideologia da ordem e do progresso, graças particularmente à atuação de Benjamim Constant (1836-1891).

O Positivismo tem na Pedagogia seguidores que merecem destaque: Herbert Spencer e John Stuart Mill. Assim sendo, o educando sofre um processo evolutivo pelo do qual revela sua potencialidade. Spencer escreveu uma obra chamada "Educação". Neste trabalho ele destacou que o ensino das ciências deve ser o centro de toda educação. Considerava a física, a química e a biologia como essenciais para a formação de um espírito científico. Stuart Mill (1806-1873) amenizou o cientificismo de Spencer para dar mais relevância às ciências sociais como a História, a Economia e o Direito.

\section{O Positivismo e a escola}

O positivismo admite apenas o que é real, verdadeiro, inquestionável, aquilo que se fundamenta na experiência. Deste modo, a escola deve privilegiar a busca do que é prático, útil, objetivo, direto e claro. Os positivistas se empenharam em combater a escola humanista, religiosa, para favorecer a ascensão das ciências exatas. As idéias positivistas influenciaram a prática pedagógica na área das ciências exatas, influenciaram a prática pedagógica na área de ensino de ciências sustentadas pela aplicação do método científico: seleção, hierarquização, observação, controle, eficácia e previsão.

\section{Classificação das ciências e educação}

A classificação das ciências proposta por Comte tem reflexos na 
educação em função da fragmentação do conhecimento e da especialização. O conhecimento fragmentado levou à elaboração de currículos multidisciplinares, restringindo qualquer tipo de relação entre diferentes disciplinas. Por meio da fundamentação e classificação das Ciências (Matemática, Astronomia, Física, Fisiologia e Sociologia), Comte acabou por exaltar e defender a superionidade das Ciências Exatas sobre as Ciências Humanas. De acordo com BOTTOMORE, "uma vez submetido o domínio das ciências humanas às disciplinas das ciência empírica, cessará a anarquia intelectual, e uma nova ordem institucional adquirirá estabilidade graças ao consenso" (1988, p. 291). Mesmo a Sociologia desenvolvida por Comte recebeu dele um caráter científico para o estudo dos fatos sociais.

\section{Ordem e progresso diante da educação}

Comte defendia a idéia de ordem industrial e o progresso nela embutido. Seu lema é "a ordem por base, o amor por princípio, o progresso por fim. O positivismo tende poderosamente, por sua natureza, a consolidar a ordem pública, através do desenvolvimento de uma sábia resignação". (MORAIS, 1983, p. 31). Os ideais de ordem e progresso na educação aparecem sob forma de disciplina e educação, respectivamente, como processo evolutivo. Por progresso entende-se que o aluno, como membro da sociedade, deve passar por fases evolutivas: o pensamento teológico, o metafísico e, por fim, 0 positivo. A superação da metafísica levaria o homem a fugir de especulações. A presença de planejamento visando ao alcance de objetivos também ilustra os ideais de ordem e progresso.

\section{Positivismo na educação brasileira}

O positivismo de Comte chegou ao Brasil em meados do século XIX. As idéias positivistas encontraram boa receptividade entre muitos oficiais do exército. Com um currículo voltado para as ciências exatas e para a engenharia, a educação se distancia da tradição humanista e acadêmica, havendo uma certa aceitação das formas de disciplina típicas do positivismo. As palavras "ordem e progresso" que fazem parte da bandeira brasileira indicam claramente a influência positivista. Na década de 70 deste mesmo século, a escola tecnicista teve uma presença marcante. A valorização da ciência como forma de conhecimento objetivo, passível de verificação rigorosa por meio da observação e da experimentação, foi importante para a fundamentação da escola tecnicista no Brasil. Para esta escola o elemento primordial é a tecnologia. Para MIUKAMI, “Qualquer estratégia instrucional com base nesta abordagem 
deve considerar a preocupação científica que a caracteriza, aplicando-a quer no planejamento quer na condução, implementação e avaliação do processo de aprendizagem. Qualquer estratégia instrucional deve, pois, estar baseada em princípios da tecnologia educacional" (1986, p. 20).

Na escola tecnicista, professores e alunos ocupam papel secundário dando lugar à organização racional dos meios. Professores e alunos relegados à condição de executores de um processo cuja concepção, planejamento, coordenação e controle, ficam a cargo de especialista supostamente habilitados, neutros, objetivos, imparciais (SAVIANI, 1993, p. 24). Portanto, pode-se perceber pelas palavras de Saviani que neutralidade e objetividade são típicas do positivismo.

\section{Para finalizar}

Sem dúvida, o Positivismo como doutrina sobre a sociedade e sobre as normas necessárias para reformar a sociedade foi um movimento que dominou uma parte significativa da cultura européia tanto no âmbito filosófico como político e pedagógico. A necessidade expressa por Comte de se estabelecer uma relação fundamental entre a ciência e a técnica concretizou-se de maneira significativa por gerações.

Na educação houve contribuições significativas no campo do planejamento escolar, uso da tecnologia, ensino profissionalizante e aplicação do conhecimento científico. Por outro lado, uma concepção puramente profissionalizante pode afetar o talento intelectual do aluno. Segundo PAVIANNI, “a concepção profissionalista dos cursos universitários é o principal entrave à existência de uma verdadeira formação universitária que tem a função de desenvolver a versatilidade intelectual da pessoa , de criar homens de mentalidade e sensíveis às necessidades dos outros homens de seu tempo" (1991, p.53).

A educação influenciada pelos ideais positivistas carece de incentivo ao desenvolvimento do pensamento crítico. A educação tecnicista apoiada nos ideais positivistas não deve reduzir-se apenas ao ensino técnico, mas deve preocupar-se também em buscar a razão do próprio procedimento técnico. Aceitar a ciência como o único conhecimento, como queria o positivismo, é algo reducionista que perde uma considerável parcela de conhecimento que não estão no dado; fica prejudicada tanto a criação como a dedução.

Por meio da educação, uma geração pode passar para futuras gerações tanto o seu aspecto físico como o espiritual. A educação tem o poder de mudar o homem e, conseqüentemente, toda uma sociedade. Como, então, considerar apenas uma dimensão da realidade, ou seja, a dimensão do que é concreto? Negar o que transcende o fato, o real, o concreto, não seria perder a chance de refletir sobre suas causas últimas? Há coisas que não podem ser explicadas ou verificadas pela experiência. As matérias de formação geral são 
fundamentais para as matérias profissionalizantes. Não seria exagero dizer que aquelas podem servir de substrato para estas. A ciência não é fonte soberana de conhecimento, como queria o Positivismo.

Por este motivo, a educação deve acontecer por intermédio da ciência, da filosofia, da religião, da arte, da ética, da virtude, etc., para não corrermos o risco da fragmentação do ensino.

\section{Referências}

BECKER, Fernando. A epistemologia do professor: o cotidiano da escola. Petrópolis : Vozes, 1993.

BOTTOMORE, Tom. (ed.). Dicionário do pensamento marxista. Rio de Janeiro : Jorge Zahar, 1988.

COMTE, Agusto. Curso de filosofia positiva. São Paulo : Abril Cultural, 1978. (Os Pensadores).

DURKHEIM, Émile. Educação e sociologia. 10. ed. São Paulo : Melhoramentos, 1975.

FREIRE, Paulo. Pedagogia da esperança: um reencontro com a pedagogia do oprimido. Rio de Janeiro: Paz e Terra, 1992.

GUIRARDELل, Paulo. Educação e razão histórica. São Paulo : Cortez, 1994.

MESQUIDA, Peri. Educação brasileira. Apostila do Curso de Mestrado em Educação. Pontifícia Universidade Católica do Paraná, Curitiba, 2001.

MORAIS FILHO, Evaristo de. Augusto Comte. Sociologia. Rio de Janeiros: Ática, 1983.

MIZUKAMI, Maria das Graças Nicoletti. Ensino: as abordagens do processo. São Paulo: EPU, 1986.

PAVIANNI, Jaime. Problemas de filosofia da educação. Petrópolis: Vozes, 1991.

SAVIANI, Dermeval. Escola e democracia. Campinas: Autores Associados, 1993.

TRIVIÑOS, Augusto. Introdução à pesquisa em ciências sociais. São Paulo: Atlas, 1987. 